\title{
A cultura da organização e a responsabilidade social empresarial
}

\section{Organization culture and the corporate social responsability}

\author{
Juliane Ruffatto ${ }^{\mathbf{i}}$ \\ Orcid: https://orcid.org/0000-0002-0406-9780
}

\author{
Jandir Pauli ${ }^{2 i i}$ \\ Orcid: http://orcid.org/0000-0003-4618-6958
}

\author{
Cláudia Silber ${ }^{3 i i i}$ \\ Orcid: https://orcid.org/0000-0003-3492-30
}

\begin{abstract}
Resumo
A cultura organizacional $(\mathrm{CO})$ como preditor de ações estratégicas é um tema emergente na análise organizacional. Entre as ações estratégicas, a decisão de implementar ações de Responsabilidade Social Empresarial (RSE) tem se mostrado um importante objeto de estudos. O objetivo desta pesquisa é descrever a influência de diferentes tipos de cultura organizacional na adoção de práticas de RSE. Com base no Competing Value Model (KIMBERLY; QUINN, 1984), este estudo discute a influência destes traços culturais específicos na adoção de práticas de RSE. Foi realizada uma survey, de corte transversal, com 187 empregados de diferentes organizações localizadas no norte do Rio Grande do Sul. Entre as conclusões, o estudo mostrou que entre os tipos culturais, o da cultura hierárquica é o que mais favorece a adoção de práticas de RSE. As características desse modelo são discutidas no artigo, indicando sua relação com o desenvolvimento destas organizações e sua relação com o contexto em que estão inseridas.

Palavras-chave: cultura organizacional; responsabilidade social empresarial; modelo de valores competitivos.
\end{abstract}

\begin{abstract}
Organizational culture as a predictor of strategic actions is an emerging theme in organizational analysis. Among the strategic actions, the decision to implement Corporate Social Responsibility (CSR) actions has proved to be an important object of studies. The objective of this research is to describe the influence of different types of organizational culture in the adoption of CSR practices. Based on the Competing Value Model (KIMBERLY; QUINN, 1984), this study discusses the influence of these specific cultural traits in the adoption of CSR practices. A cross-sectional survey was carried out with 187 employees from different organizations located in the north of Rio Grande do Sul. Among the conclusions, the study showed that among cultural types, that of hierarchical culture is the one that most favors the adoption of practices of CSR. The characteristics of this model are discussed in the article, indicating its relationship with the development of these organizations and its relationship with the context in which they are inserted.

Keywords: organizational culture; corporate social responsibility; competitive values model.
\end{abstract}

\footnotetext{
${ }^{1}$ Universidade do Vale do Rio do Sinos - UNISINOS, Brasil. E-mail: julianerufato@hotmail.com

${ }^{2}$ Faculdade Meridional - IMED, Brasil. E-mail: jandir.pauli@imed.edu.br

${ }^{3}$ Universidade do Vale do Rio do Sinos - UNISINOS, Brasil. E-mail: claudiasilber@live.com
} 


\section{INTRODUÇÃO}

Apesar do conceito de Cultura Organizacional (CO) ser de difícil definição devido à diversidade de fatores ou dimensões que o conceito evoca (MIGUELES, 2003), estudos publicados na última década evidenciam a influência de elementos do comportamento organizacional, anteriores ao processo de tomada de decisão, na adoção da RSE. Um desses elementos é a cultura organizacional, uma vez que esta define a identidade e orientação que influencia decisões sobre a priorização, comprometimento e continuidade, além de servir como dispositivo para a tomada de decisão estratégica (SMIRCICH, 1983). A cultura organizacional emerge, assim, como uma preditora importante da organização sistêmica e contribui para embasar decisões que influenciam na obtenção de resultados (HARTNELL et al., 2019).

Para Chams e García-Blandón (2019), o desenvolvimento da consciência sobre aspectos da sustentabilidade no contexto organizacional se origina na gestão sustentável dos recursos humanos, ao estabelecer diretrizes para atitudes e comportamentos. Nessa perspectiva, é a cultura organizacional que pode promover a RSE, ao favorecer o envolvimento, participação e engajamento de stakeholders internos e externos, além de produzir um efeito sinérgico sobre a implementação de processos e a realização de práticas que influenciam no desempenho social da empresa (TANTALO; PRIEM, 2016).

Considerada como antecedente da postura socialmente responsável, a $\mathrm{CO}$ se manifesta inter e intraorganizacionalmente, por meio da adoção de visões e estratégias sustentáveis, que orientam a atitude, moral e comportamentos. A cultura organizacional está presente em três níveis: i) no nível superficial: identificada por meio de artefatos; ii) no nível de valor: alcançada por meio de normas e crenças compartilhadas entre indivíduos, equipes e empresas; e, iii) no nível subjacente: adotando princípios que refletem a interconexão entre os humanos e os ecossistemas (CHAMS; GARCÍABLANDÓN, 2019, p. 115).

Nesse sentido, ao se estabelecer uma relação entre cultura e adoção de práticas de RSE, constata-se a existência de divergências quanto à amplitude da análise (cultura da região ou país versus cultura da organização), e em relação aos modelos teóricos que sugerem diferentes constructos e acepções para mensurar uma cultura organizacional (DUARTE, 2010; HUEMER, 2010; RISHI; MOGHE, 2013; PASRICHA; SINGH; VERMA, 2018).

Conforme aponta o estudo de Dogle e Holtburgge (2013), a globalização gera efeitos que minimizam possíveis diferenças culturais regionais que influenciam na percepção dos funcionários sobre a reputação organizacional, para a qual a RSE é considerada como um fator relevante para a construção da imagem da empresa (AGUILERA et al., 2017). Contudo, algumas culturas, principalmente as de países economicamente desenvolvidos, tendem a favorecer as práticas RSE, porque nesses mercados os consumidores percebem os aspectos da sustentabilidade como um valor de diferenciação. Consequentemente, os consumidores são mais dispostos a pagar preço superior por produtos de empresas que adotam postura socialmente responsável (SHEA; HAWN, 2019).

O tema RSE tem recebido destaque no contexto dos estudos organizacionais (CARROLL, 1999; WOOD, 1991). Revelada como um atributo relevante para a reputação empresarial, a adoção de atitude socialmente responsável passou a ser um dos focos de atenção das atividades empresariais contemporâneas (AGUILERA et al., 2017; JAMALI; KARAM, 2018).

Iniciativas que combinam a atividade principal e outras relacionadas com a RSE, demandam que empresas assumam compromissos com a realização 
de ações que geram benefícios para a sociedade e, com o mesmo empenho, pratiquem relacionamentos transparentes com os stakeholders, seguindo pressupostos que orientam as boas práticas da governança corporativa, em linha com valores morais e atitude ética (FREEMAN; EVAN, 1990; MAON; LINDGREEN; SWAEN, 2010).

Em relação às motivações das empresas para a adoção da SER, podem ser analisadas sob perspectivas distintas, mas quanto ao âmbito externo, a pressão dos stakeholders é considerada um dos fatores mais relevantes (ABREU et al., 2015). Nesse contexto, a participação dos funcionários nas práticas de RSE é um recurso que fortalece a legitimidade da empresa em suas iniciativas, tanto dentro como fora do ambiente organizacional (MITCHEL; AGLE; WOOD, 1997). Nessa perspectiva, o envolvimento dos funcionários com a RSE agrega diferencial competitivo (MATTIOLI et al., 2015). Também, por serem os funcionários classificados como parte dos stakeholders primários e internos (CLARKSON, 1994), essenciais na realização das atividades e na construção da reputação da empresa, o que justifica a escolha da amostra pesquisada (FERNANDEZ; JUNQUERA; ORDIZ, 2003; TURKER, 2009; SULKOWSKI; EDWARDS; FREEMAN, 2018).

Este artigo segue a conclusão de Gupta, Briscoe e Hambrick (2017) sobre a concentração de estudos na ênfase das pressões externas e de stakeholders, bem como as preferências dos CEOs para adoção de estratégias de RSE, dando pouca importância à possibilidade de que a RSE também possa derivar das crenças compartilhadas pelos membros da empresa. Considera-se, assim, que há evidências de que a cultura das organizações pode ser um vetor das práticas de responsabilidade social (RODRIGO; ARENAS, 2008; STRAUTMANIS, 2008), abrindo uma lacuna para pesquisas sobre a capacidade preditiva da cultura organizacional na adoção das práticas de RSE.
Para este estudo, adotou-se o modelo de valores competitivos de Kimberly e Quinn (1984) - também conhecido como Tipologia Cultural de Quinn - para descrever a relação entre os traços predominantes de uma cultura organizacional na adoção de práticas de RSE. O modelo proposto por Kimberly e Quinn (1984) denominado Competing Value Model (modelo de valores competitivos) serve de métrica para análises transorganizacionais e interculturais. $\mathrm{O}$ modelo assume que as organizações podem ser caracterizadas de acordo com seus traços culturais comuns. Esse instrumento é eficaz para definir quatro tipos de cultura organizacional (clã, inovativa, de mercado e hierárquica), para interpretar os seus atributos e estudar a cultura em termos comparativos (KIMBERLY; QUINN, 1984).

Para oferecer subsídios a essa discussão, inicialmente são apresentadas as bases teóricas relativas a cada construto e os respectivos modelos selecionados para utilização no estudo empírico. Em seguida, comentam-se os indícios teóricos de associação entre os temas de cultura e responsabilidade social empresarial. Nos tópicos seguintes apresentam-se os aspectos metodológicos da pesquisa de campo e a discussão dos resultados, encerrando-se o estudo com as considerações finais.

\section{FUNDAMENTAÇÃO TEÓRICA}

\subsection{Cultura organizacional}

Os estudos sobre cultura organizacional surgiram de forma muito marcante nos estudos organizacionais na década de 80 , esse fato se dá pelos estudos clássicos da cultura organizacional (DEAL; KENNEDY, 1982; PETERS; WATERMAN, 1982; GORDON, 1985; SCHEIN, 1985; CAMERON; FREEMAN, 1990; YEUNG; BROCKBANK; ULRICH, 1991) dando enfoque para os diferentes tipos de cultura e para a intensidade da força cultural apresentada pela empresa. 
Tanto no âmbito acadêmico quanto no empresarial, os dois temas têm atraído considerável atenção. $\mathrm{Na}$ academia, os estudos de cultura dão enfoque às abordagens mais subjetivistas, como os de Edgar Schein (1984; 1996), ou então, os que se dedicam ao objetivismo (HOFSTEDE et al., 1990; ARDICHVILI et al., 2012; DUPUIS, 2014) e comparam as culturas organizacionais entre diferentes países. Esse conceito, contudo, não é homogêneo, pois há um grande arcabouço de diferentes definições a respeito desse tema (SMIRCICH, 1983).

De acordo com Fleury e Fischer (1989) a cultura possui a característica de ser formada por uma gama de pressupostos e valores expressos por elementos simbólicos, construindo identidades organizacionais e funcionando como um instrumento para relações de dominação. A cultura tem por característica ser aprendida e compartilhada, além de inter-relacionar suas diferentes facetas em um só grupo (HALL, 1978).

$\mathrm{Na}$ literatura pesquisada sobre $\mathrm{CO}$, foram identificados modelos teóricos sobre perspectivas distintas que possibilitam uma visão holística sobre a cultura das organizações, destinando-se a investigar diferentes traços, tipos e elementos nesse contexto (SCHEIN, 1991; ROUSSEAU,
1990; HOFSTEDE et al., 1990). Porém, o modelo de Kimberly e Quinn (1984), intitulado como Competing Value Model (Modelo de valores competitivos), possibilita a identificação de diferentes tipos de culturas existentes em um mesmo contexto organizacional ou em um grupo específico. Com abordagem quantitativa, esse modelo oferece uma visão distinta do modelo qualitativo tradicional, geralmente utilizado neste tipo de investigação (SANTOS, 1998).

O modelo de Kimberly e Quinn (1984) permite analisar os diferentes traços culturais existentes nos contextos organizacionais, e possibilita organizar distintos aspectos que constituem a cultura organizacional, tais como: valores, crenças e padrões de comportamento. Neste sentido, ele está estruturado em duas dimensões, de onde emergem quatro tipologias culturais distintas para formar a tipologia de Quinn (SANTOS, 1998). Segundo Kimberly e Quinn (1984), as dimensões e os valores pertencentes a esta abordagem ajudarão na exploração da cultura organizacional e a forma com que ela é constituída.

Os tipos culturais se dividem em quatro quadrantes (Figura 1), dividindo-se em: cultura clã ou de grupo, cultura inovadora, cultura hierárquica e cultura de mercado.

Figura 1 - Modelo de valores competitivos

\section{FLEXIBILIDADE E LIBERDADE}

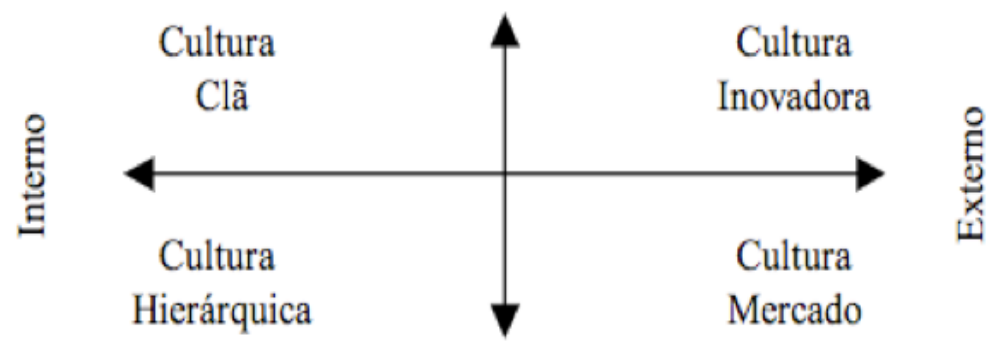

ESTABILIDADE E CONTROLE

O primeiro quadrante refere-se a cultura clã, que enfatiza uma cultura focada na tomada de decisões em grupo, e o desenvolvimento do sistema de gestão de 
pessoas. Nesse quadrante os líderes devem sempre facilitar a interação entre a equipe, estimular sua lealdade e demostrar que a remuneração será apoiada no grupo e não individualmente (KIMBERLY; QUINN, 1984).

A cultura inovadora pertence ao segundo quadrante, e possui características voltadas à criatividade, inovação e crescimento. Esta cultura apresenta uma estrutura mais flexível e moldável, de forma que os líderes e gerentes exerçam uma ideologia empreendedora, com foco voltado a assumir riscos (KIMBERLY; QUINN, 1984).

Em oposição ao segundo quadrante, a cultura hierárquica está diretamente associada a uma estrutura com maior rigidez, burocrática e estável. Dessa forma, nessa cultura a autoridade toma as decisões a serem seguidas pela equipe. Nesse modelo, os líderes são mais conservadores e cautelosos (KIMBERLY; QUINN, 1984).

Já o quarto quadrante refere-se à cultura mercado. Nesse tipo de cultura a ênfase está nos resultados préestabelecidos, com foco no desempenho e competitividade entre a equipe. Com base nesses fatores, os líderes desse quadrante devem ter o perfil de motivadores, constantemente encorajando sua equipe a produzir mais (KIMBERLY; QUINN, 1984).

Os tipos de cultura também são distintos em enfoques, valores e orientações, de maneira que se assemelham em alguns pontos, e em outros são extremamente opostos, como pode ser observado no Quadro 1 abaixo:

Quadro 1 - Perfis, Valores e Processos de informação de cada cultura

\begin{tabular}{|l|l|l|l|}
\hline Tipo de Cultura & Perfil & Valores & Processo de informação \\
\hline Cultura Clã & $\begin{array}{l}\text { Flexibilidade; } \\
\text { Enfoque Interno; }\end{array}$ & Coesão e Moral; & Processo Coletivo; \\
\hline Cultura Inovadora & $\begin{array}{l}\text { Flexibilidade; } \\
\text { Enfoque Externo; }\end{array}$ & Valores e flexibilidade; & Processo Intuitivo; \\
\hline Cultura Hierárquica & $\begin{array}{l}\text { Controle; } \\
\text { Enfoque Interno; }\end{array}$ & $\begin{array}{l}\text { Administração da informação; } \\
\text { Comunicação; }\end{array}$ & Processo documental; \\
\hline Cultura Mercado & $\begin{array}{l}\text { Controle; } \\
\text { Enfoque Externo; }\end{array}$ & Maior lucro e produtividade & Processo Individual; \\
\hline
\end{tabular}

Fonte: adaptado de Kimberly e Quinn (1984).

Howard (1998) em seus estudos testou o modelo de valores competitivos de Kimberly e Quinn (1984) e concluiu que o modelo fornece uma métrica válida para compreensão e comparação de culturas organizacionais. Ainda, o instrumento se mostrou eficaz para avaliar culturas organizacionais em relação a outras variáveis. Outros estudos (KWAN; WALKER, 2004; DA SILVA; DE SÁ, 2016) também empregaram a tipologia cultural de Quinn, validando a escala para a cultura organizacional de empresas brasileiras. O intuito desses estudos foi confirmar que o modelo não só pode ser usado para descrever a cultura de uma organização, mas também pode servir como uma base válida para diferenciar uma da outra.

\subsection{Responsabilidade Social Empresarial}

As organizações normalmente estão permeadas por abordagens relacionadas ao comportamento ético, considerando os efeitos de suas ações para a sociedade e para o meio ambiente. Sob essas perspectivas, as organizações não percebidas como atores independentes, mas como parte de um ecossistema relacionado a fatores sociais e 
ambientais (WOOD, 1991). Essa dimensão, conectada com a atuação da organização é denominada em termos teóricos como Responsabilidade Social Empresarial (RSE), que é definida como um conjunto de compromissos dos gestores em tomar decisões e seguir uma linha de ação coerente com os valores inseridos na sociedade (BOWER, 1957).

O estudo de Carroll (1979) sedimentou o conceito de RSE em forma de pirâmide, sustentando quatro diferentes formas de responsabilidade - econômicas, éticas, legais e filantrópicas. Associado a esse conceito, o termo "Iniciativas de Responsabilidade Social Empresarial" é definido como as diferentes formas de uma organização se envolver em ações de filantropia, sendo apoiadora para a viabilidade de organizações sem fins lucrativos.

Um dos principais benefícios trazidos pelas inciativas de RSE para as organizações é a melhoria da imagem organizacional, consequência da identificação dos seus clientes com a empresa, a partir do momento que iniciativas são bem-sucedidas, contribuindo para a superação do autoconceito do consumidor ao gerar reflexos positivos para a reputação da organização (CHOI; WANG, 2009).

Dessa maneira, os clientes tendem a ter maior grau de simpatia e identificação com a empresa, e consequentemente, ter uma maior aceitação e tolerância com ela (LICHTENSTEIN; DRUMWRIGHT; BRAIG, 2004). Em adição a isso, os estudos de Lichtenstein, Drumwright e Braig (2004) validam a hipótese de que as iniciativas de RSE melhoram a identificação não apenas do cliente com a organização que realizou a ação, como também com as organizações sem fins lucrativos que recebem essa doação, ampliando os efeitos positivos para um círculo mais amplo de stakeholders (LICHTENSTEIN; DRUMWRIGHT; BRAIG, 2004).

Iniciativas de RSE mostraram-se influenciadoras em relação ao desempenho financeiro e organizacional das empresas (MCGUIRE et al., 1988; GRAVES; WADDOCK, 1994; GRIFFIN; MAHON, 1997). Estudos como o de Turker (2009) buscaram identificar como essas iniciativas afetariam os empregados da organização. Em um contexto de empresa chinesa, o estudo de Wang e Juslin (2009) confirmou a relação positiva entre as iniciativas de RSE com a cultura do país.

Em um estudo que relacionou cultura organizacional com responsabilidade social, Leandro e Rebelo (2011) inferem que a grande diferença para uma organização se situa na construção inevitável versus a imposição desejada da cultura organizacional e da responsabilidade social, respectivamente. Para os autores, considerando que a cultura é uma construção dos atores organizacionais, a responsabilidade social redunda num conjunto de políticas e práticas impostas e/ou sugeridas pela gestão de topo da organização, com a expectativa de que esta seja disseminada por todos os atores na organização, o que não obrigatoriamente resultará em construção de sentidos coletivos (LEANDRO; REBELO, 2011).

Maon, Lindgreen e Swaen (2010) propõem um modelo integrado de sete estágios de desenvolvimento da RSE, que gira em torno de três fases culturais (relutância de RSE, alcance de RSE e implementação da RSE). Os autores afirmam que há relações de contingência entre a cultura dominante das partes interessadas (stakeholders) de uma organização e sua propensão e capacidade para responder às expectativas sociais, que por sua vez, determina a natureza e o escopo do desenvolvimento de seus compromissos de RSE (MAON; LINDGREEN; SWAEN, 2010).

\section{MÉTODO}

Esta pesquisa pode ser definida como de natureza descritiva, já que pretende descrever uma relação entre 
variáveis, de abordagem quantitativa, e de corte transversal (MALHOTRA, 2011), pois os dados foram coletados uma única vez para a amostra. O público-alvo da pesquisa foram empregados de organizações de diferentes setores econômicos. Para tanto, compuseram a amostra 187 indivíduos selecionados pela técnica de amostragem não probabilística, por conveniência, pois não foi possível conhecer todos os elementos que compõem a população para selecionar os respondentes de forma aleatória.

A fim de atingir o maior número possível de empresas, o acesso a uma escola de negócios apresentou-se como o meio mais viável para determinado fim, sendo que o critério de inclusão na pesquisa foi a existência de um vínculo de trabalho formal a uma empresa. Os alunos do curso de administração da escola de negócios foram inquiridos, inicialmente, a respeito do vínculo de trabalho formal a uma empresa. Somente fizeram parte do grupo amostral, os casos que apontaram estarem vinculados a uma organização, o que permitiu heterogeneidade na amostra, quanto à diversidade de empresas que compuseram a pesquisa.

Diante do objeto de estudo de verificar a relação dos tipos de cultura (variável independente) com a responsabilidade social empresarial (variável dependente), e identificar qual o tipo e cultura predominante entre as empresas analisadas, os dados necessários foram coletados por meio de um questionário estruturado construído a partir de escalas já existentes, validadas em outros estudos e dividido em duas partes: na primeira, utilizou-se o instrumento para mensurar cultura de Kimberly e Quinn (1984), intitulado Competing Value Model (CVM) ou Modelo de Valores Competitivos. O modelo provê um instrumento composto por 24 itens, capaz de identificar diferentes perfis culturais que são evidenciados pelas culturas: grupal, inovativa, racional ou de mercado e hierárquica, medidos por meio de uma escala do tipo Likert de sete pontos.

$\mathrm{Na}$ segunda parte, a escala para medir a percepção do indivíduo sobre a responsabilidade social empresarial da empresa, de Lichtenstenstein et al. (2004) composta por 5 itens. Essas variáveis foram medidas por uma escala do tipo Likert de sete pontos ( 1 para discordo totalmente e 7 para concordo totalmente). Por último, o questionário continha questões relacionadas a dados socioeconômicos, tais como idade e sexo e variáveis de controle como por exemplo o tempo de empresa.

Para o tratamento dos dados, utilizou-se o software Statistical Package for the Social Sciences (SPSS), versão 20.0. Para a análise das variáveis, foram realizadas estatísticas descritivas a cada grupo de variáveis. Também foi realizado o teste de confiabilidade (Alfa de Cronbach) das escalas adotadas e também análise da variância (ANOVA) para comparação de médias (HAIR et al., 2005) entre os tipos culturais para verificar qual o tipo mais presente.

Para verificar a relação entre os tipos culturais e a responsabilidade social empresarial, foi realizado o teste de correlação de Spearman e análise de regressão, a fim de aferir o efeito da variável independente (tipos culturais) na dependente (RSE). Na análise de regressão, o tamanho do efeito foi obtido por meio dos coeficientes de regressão padronizados, calculados para cada modelo (HAIR et al., 2005).

Por meio de questionários impressos, a coleta de dados foi feita nos meses de maio e junho de 2019, nas dependências de uma escola de negócios localizada no Rio Grande do Sul. Institui-se o critério de vínculo empregatício, resultando na participação de 187 alunos, que responderam à pesquisa em sala de aula.

\section{RESULTADOS}

\subsection{Perfil da amostra}


Foram aplicados 187 questionários para a realização desta pesquisa quantitativa, sendo que a maioria $(56 \%)$ dos respondentes pertencem ao sexo feminino e apresentam idade média de 24 anos. Com relação ao tempo que cada entrevistado trabalha na empresa, é possível verificar que $42,9 \%$ trabalham entre 1 e 5 anos, seguidos de $20,5 \%$ que trabalha a menos de 1 ano. Por fim, respondentes que trabalham na empresa entre 5 e 10 anos representam $20 \%$ e mais de 10 anos representam $16,7 \%$.

\subsection{Estatísticas Descritivas}

Diante do objetivo do estudo de verificar a relação dos tipos de cultura organizacional com a responsabilidade social empresarial entre diferentes empresas, e identificar qual o tipo de cultura predominante dentro dessas empresas, foram realizados testes estatísticos, identificando os elementos considerados de maior importância pelos integrantes das empresas no desenvolvimento de uma cultura organizacional adequada à realidade, e o grau de importância que os mesmos têm atribuído à cultura organizacional e à responsabilidade social empresarial. O tipo cultural mais presente entre as organizações pesquisadas foi o da cultura racional ou de mercado $(M=4,971$; $F=8,621$ e $p<0,001)$; o segundo tipo cultural que mais aparece nas organizações pesquisadas foi o da cultura hierárquica $(M$ $=4,826 ; F=6,901$ e $p<0,001$ ), seguido pela cultura clã $(M=4,759 ; \quad F=9,658$ e $p<0,001)$, e por último, o tipo de cultura inovativa $(M=4,703 ; F=9,251$ e $p<0,001)$ menos presente nas organizações investigadas.

Pode-se inferir que existem diferenças estatisticamente significativas entre a cultura racional relativamente aos demais tipos culturais. Esse tipo está disposto a buscar melhores resultados organizacionais por meio da competitividade e produtividade, os quais são alcançados através de uma ênfase no posicionamento e controle externo. Esta cultura reflete que quanto maior for $\mathrm{o}$ desempenho e os resultados, maior a remuneração (KIMBERLY; QUINN, 1984).

Nesse tipo de cultura, os valores estão voltados para o controle e no foco para o ambiente externo (mercado). Os líderes enfatizam a fixação de metas como meio para estímulo da produtividade, assumindo atitude severa e exigente. O elemento que fundamenta a organização é a ênfase no vencedor (HOWARD, 1998). Essas características podem ser observadas nas empresas da região onde foi realizada a pesquisa, muitas delas de cunho familiar, e que têm sua economia baseada na oferta de comércio e serviço, configurando um ambiente de negócios altamente competitivo.

Quanto à responsabilidade social, devido à alta variabilidade de respostas $(D P$ $=1,499)$, não se pôde determinar, nas organizações pesquisadas, o nível de percepção dos funcionários quanto às práticas de responsabilidade social, se alto ou baixo. Dentre as cinco variáveis observáveis do construto Responsabilidade Social Empresarial, vale destacar a que mediu a percepção dos empregados quanto à valorização dos empregados em suas atividades no local de trabalho ("O local onde trabalho valoriza os seus funcionários em suas atividades") $(M=4,57 ; F=4,155$ e $p<0,001)$, demonstrando a relevância da valorização do funcionário em suas atividades para o desenvolvimento de uma cultura voltada à RSE (LICHTENSTENSTEIN et al., 2004).

Para verificar a confiabilidade das duas escalas adotadas nesse estudo, empregou-se o teste de confiabilidade de escalas (Alpha de Cronbach). Para os dois construtos (tipos de cultura e responsabilidade social empresarial), os índices ficaram superiores aos considerados desejados, ou seja, maiores que 0,7 (HAIR et al., 2005). 


\subsection{Análise das variáveis}

Para testar a relação entre a responsabilidade social empresarial e os tipos de cultura, realizou-se o teste de correlação de Pearson (Tabela 2).

Tabela 2 - Correlação de Pearson

\begin{tabular}{|c|c|c|c|c|c|}
\hline & RSE & Cultura Clã & $\begin{array}{c}\text { Cultura } \\
\text { Inovativa }\end{array}$ & $\begin{array}{c}\text { Cultura } \\
\text { Racional }\end{array}$ & $\begin{array}{c}\text { Cultura } \\
\text { Hierárquica }\end{array}$ \\
\hline ser & 1 & & & & \\
\hline Cultura Clã & $0,399 *$ & 1 & & & \\
\hline Cultura Inovativa & $0,356^{*}$ & $0,820 *$ & 1 & & \\
\hline Cultura Racional & $0,411^{*}$ & $0,669 *$ & $0,733 *$ & 1 & \\
\hline Cultura Hierárquica & $0,547 *$ & $0,668 *$ & $0,675^{*}$ & $0,827 *$ & 1 \\
\hline
\end{tabular}

*A correlação é significativa no nível $\mathrm{p}<0,001$.

Fonte: Dados da pesquisa do relatório do SPSS (2019).

O teste de correlação de Pearson permite verificar uma correlação positiva entre os construtos responsabilidade social empresarial e os tipos de cultura. Todos os tipos culturais apresentaram correlação significativa e positiva com a percepção de RSE, sendo mais forte para a cultura hierárquica $(r=0,547)$. Dessa forma, observa-se que para os quatro tipos culturais a hipótese nula $(\mathrm{H} 0)$ é rejeitada ( $p$-valor $<0,001)$, e os tipos de cultura estão relacionados positivamente com a percepção de responsabilidade social nas empresas abordadas, e que nas empresas com prevalência da cultura hierárquica, a percepção de RSE é maior.

Para analisar a interferência dos tipos de cultura (variável independente) na responsabilidade social empresarial (variável dependente), foi realizada a regressão linear (Tabela 3) com os quatro tipos culturais, pois todas as quatro culturas correlacionaram-se positiva e significativamente com a RSE.

Tabela 3 - Regressão RSE

\begin{tabular}{lllc}
\hline \multicolumn{1}{c}{ Variáveis Independentes } & B & t & Significância \\
\hline Cultura Clã & 0,179 & 1,073 & 0,285 \\
\hline Cultura Inovativa & $-0,086$ & $-0,545$ & 0,587 \\
\hline Cultura Racional & $-0,190$ & $-0,976$ & 0,331 \\
\hline Cultura Hierárquica & 0,868 & 4,629 & 0,000 \\
\hline
\end{tabular}

a. Variável Dependente: RSE

Fonte: Dados da pesquisa do relatório do SPSS (2019).

O resumo do modelo foi um $\mathrm{R}^{2}$ de 0,311, que mede o quanto o modelo consegue explicar a variabilidade da RSE (HAIR et al., 2005), isso é, os tipos culturais explicam $31,1 \%$ da variação da percepção da RSE em função dos tipos culturais.

$\mathrm{O}$ resultado preditivo da $\mathrm{CO}$ sobre a RSE pode ser considerado expressivo, uma vez que o constructo RSE abarca um conjunto de práticas de relacionamento entre empresas e seu contexto social. O resultado também reforça a ideia de Tantalo e Priem (2016), de que a CO pode promover a SER, e de Chams e García-Blandón (2019) sobre os possíveis efeitos positivos da gestão sustentável de recursos humanos ao estabelecer diretrizes para atitudes e comportamentos nas empresas. 
O tipo cultural que interfere de maneira significativa na RSE é a cultura hierárquica, que é aquela que demonstra os valores e normas associadas à burocracia. A cultura é norteada por pressupostos de estabilidade; empregados aceitam a autoridade formalmente estabelecida, com regras e regulamentos impostos (KIMBERLY; QUINN, 1984). Diante dos resultados encontrados, é possível inferir que alguns valores culturais, como aqueles voltados para o controle e um foco interno que incluem comunicação e formalização, assim como a centralização de decisões para alcançar a estabilidade, característicos da cultura hierárquica, podem influenciar as práticas de responsabilidade social empresarial.

Este tipo de cultura é permeado por pressupostos de estabilidade, e reflete os valores e normas associados à burocracia. De acordo com essa orientação cultural, os empregados aceitam bem a autoridade que emana de papeis formalmente estabelecidos, de regras e regulamentos impostos, sugerindo que os fatores de motivação incluem segurança e ordem. Os líderes tendem a ser conservadores em relação aos problemas de natureza técnica (KIMBERLY; QUINN, 1984).

Os resultados corroboram achados de estudos anteriores, de que elementos associados ao comportamento organizacional, como estilo de liderança e traços de $\mathrm{CO}$ influenciam em favor do envolvimento da empresa em práticas de RSE (WALDMANN et al., 2006; HEJJAS; SCARLES, 2018). Também é possível inferir sobre a potência das preferências do dirigente máximo da empresa, na opção por aderir às práticas de RSE (GUPTA; BRISCO; HAMBRICK, 2017), indicando que esse tema está positivamente associado às decisões mais centralizadas e derivadas da hierarquia (LEANDRO; REBELO, 2011).

Os resultados também convergem com o estudo realizado por Almeida e Sobral (2007) no Brasil, que por meio de uma escala focada em atitudes dos gestores perante a RSE, evidencia que gestores conservadores são os que possuem maior relação com ações positivas ao contexto social em que estão envolvidos. São organizações que evoluíram do modelo tradicional, mas com características de organizações burocráticas, com gestão local, porém com viabilidade e autonomia que refletem elementos da cultura local (LENZIARDI, 2016).

Ainda, o resultado alinha-se com a ideia de Maon, Lindgreen e Swaen (2010), de que que são as organizações que devem proporcionar as condições para a alavancagem de uma cultura organizacional voltada à RSE, e que isso só é possível quando todos na organização compartilham da mesma ideia, as informações são compartilhadas e os empregados não impõem barreiras e resistências às decisões dos gestores, pois percebem os resultados positivos de tais práticas e os benefícios gerados pelo bom relacionamento com os stakeholders.

Importante considerar que os resultados encontram eco na definição de cultura hierárquica de Kimberly e Quinn (1984), segundo a qual, em organizações com este traço cultural, os empregados aceitam a autoridade formalmente constituída e os regulamentos que dele emanam.

\section{CONSIDERAÇÕES FINAIS}

O objetivo deste estudo foi verificar a influência dos tipos de cultura organizacional na predisposição para o desenvolvimento de iniciativas de responsabilidade social, no intuito de identificar o tipo de cultura predominante entre as empresas pesquisadas. Ao confirmar que a RSE está associada à cultura organizacional, a pesquisa contribuiu para evidenciar a existência de uma correlação positiva entre os tipos de cultura organizacional e as iniciativas de RSE realizadas, permitindo algumas conclusões, de acordo com a questão de pesquisa. 
O resultado de que o tipo de cultura hierárquica, que estabelece posições bem definidas dentro das organizações, é um preditor de práticas de responsabilidade social abre caminhos para futuras pesquisas, a fim de comprovar sobre quais elementos da cultura hierárquica acabam reforçando a RSE. Nessa direção, parece razoável afirmar que a RSE é introduzida nas empresas por uma pressão externa, captada pelos dirigentes máximos da empresa para, em seguida, ser internalizada e compartilhada entre os empregados, tornando-se um elemento amplamente aceito.

Dito de outra forma, os resultados permitem propor a discussão de que a criação de uma cultura de RSE não é somente resultado de crenças construídas e compartilhadas pelos empregados, mas derivadas da hierarquia da empresa. Nesse sentido, estudos futuros poderiam explorar a natureza dessas escolhas, prevendo se estão associadas a valores normativos dos dirigentes ou se são uma opção estratégica da empresa.

Entre as limitações do estudo está a dificuldade de generalização em razão da natureza da variável $\mathrm{CO}$, considerando fatores externos como a cultura do país e mesmo as diferenças regionais típicas de países com grande extensão territorial, como o Brasil. Nesse sentido, serão necessários mais estudos em outras regiões para fins de comparação.

Outro fator a ser considerado entre as limitações é de que este estudo não considerou as quatro diferentes formas de RSE (econômicas, éticas, legais e filantrópicas) para avaliar possíveis diferenças entre os grupos e sua relação com a CO. Essa opção poderia contribuir para melhor compreensão das especificidades do conceito de RSE, como por exemplo, a influência de ações com apelo ético para internalização de padrões culturais nas empresas.

Um terceiro aspecto a considerar em estudos futuros é a possibilidade de realização de um estudo que inclua um espectro mais amplo de setores e portes de empresa. Esse estudo considerou apenas o vínculo empregatício como critério de análise, e a amostra não foi direcionada para um setor econômico ou porte específico de empresa.

Estudos futuros poderiam, por exemplo, fazer esse recorte para permitir avaliar possíveis diferenças entre empresas familiares, pequenas e médias empresas e empresas de grande porte, especialmente as de capital aberto, por possuírem práticas de gestão de stakeholders formalmente instituídas. Na mesma direção, estudos poderiam diferenciar as empresas que produzem um volume maior de rejeitos ou exploração de recursos naturais, além de avaliar o grau de maturidade das ações de RSE e sua associação com políticas de recursos humanos instituídas.

Mesmo considerando estas limitações, acredita-se que este estudo alcançou seus objetivos por trazer uma relação altamente significativa entre a $\mathrm{CO}$ e a RSE, permitindo uma discussão sobre a relação entre as crenças compartilhadas dentro da organização com as ações da empresa com seus stakeholders. Seus achados permitem criar uma imagem mais interrelacionada da empresa com o seu entorno, além de sugerir um movimento de abertura das empresas para estruturar ações de colaboração com a sociedade e a preservação dos recursos naturais, melhorando sua reputação externa e criando um maior senso de propósito entre os empregados.

\section{REFERÊNCIAS}

AGUILERA-CARACUEL, Javier; GUERRERO-VILLEGAS, Jaime; GARCÍA-SÁNCHEZ, Encarnación. Reputation of multinational companies. European Journal of Management and Business Economics, v. 26, n. 3, p. 329346, 2017.

ALMEIDA, Filipe; SOBRAL, Filipe. A influência dos valores culturais na 
Responsabilidade Social das Empresas: Um estudo empírico sobre a atitude dos gestores brasileiros. Revista portuguesa e brasileira de gestão, v. 6, n. 3, p. 51-61, 2007.

ARDICHVILI, Alexandre; JONDLE, Douglas, KOWSKE, Brenda, CORNACHIONE, Edgard, Li, Jessica, THAKADIPURAM, Thomas. Ethical cultures in large business organizations in Brazil, Russia, India, and China. Journal of Business Ethics, v. 105, n. 4, p. 415428, 2012.

BOWER, Howard R. Responsabilidades sociais dos homens de negócio. Rio de Janeiro: Editora Civilização Brasileira S.A, 1957.

CAMERON, Kim S.; FREEMAN, Sarah J. Cultural congruence strength and type. In: Academy of Management Meeting. Washington, DC, 1990.

CARROLL, Archie B. A threedimensional conceptual model of corporate performance. Academy of management review, v. 4, n. 4, p. 497-505, 1979.

CARROLL, Archie B. Corporate Social Responsibility: evolution of a definitional construct. Business and Society, v. 38, n. 3, p. 268-295, 1999.

CHAMS, Nour; GARCÍA-BLANDÓN, Josep. On the importance of sustainable human resource management for the adoption of sustainable development goals. Resources, Conservation and Recycling, v. 141, p. 109-122, 2019.

CHOI, Jaepil; WANG, Heli. Stakeholder relations and the persistence of corporate financial performance. Strategic management journal, v. 30 , n. 8, p. 895907, 2009.

CLARKSON, Max E. A stakeholder framework for analyzing and evaluating corporate social performance. Academy of management review, v. 20, n. 1, p. 92117, 1995.

DEAL, Terrence E.; KENNEDY, Allan A. Corporate cultures: The rites and rituals of organizational life. Reading/T. Deal, A. Kennedy.-Mass: Addison-Wesley, v. 2, p. $98-103,1982$.

DÖGL, Corinna; HOLTBRÜGGE, Dirk. Corporate environmental responsibility, employer reputation and employee commitment: an empirical study in developed and emerging economies. International Journal of Human Resources Management, v. 25, n. 12, p. 1739-1762, 2013.

DUARTE, Fernanda. Working with corporate social responsibility in Brazilian companies: The role of managers' values in the maintenance of CSR cultures. Journal of Business ethics, v. 96, n. 3, p. 355-368, 2010.

DUPUIS, Jean-Pierre. New approaches in cross-cultural management research. The importance of context and meaning in the perception of management styles. International Journal of Cross Cultural Management, v. 14, n. 1, p. 6784, 2014.

FAROOQ, Omer; RUPP, Deborah E.; FAROOQ, Mariam. The multiple pathways through which internal and external corporate social responsibility influence organizational identification and multifoci outcomes: The moderating role of cultural and social orientations. Academy of Management Journal, v. 60, n. 3, p. 954-985, 2017.

FERNÁNDEZ, Esteban; JUNQUERA, Beatriz; ORDIZ, Mónica. Organizational culture and human resources in the environmental issue: a review of the literature. International Journal of Human 
Resource Management, v. 14, n. 4, p. 634-656, 2003

FLEURY, Maria Tereza Leme; FISCHER, Rosa Maria. Cultura e poder nas organizações. Atlas, 1989.

FREEMAN, R. Edward; EVAN, William M. Corporate governance: A stakeholder interpretation. Journal of behavioral economics, v. 19, n. 4, p. 337-359, 1990.

GALBREATH, Jeremy. Building corporate social responsibility into strategy. European business review, v. 21, n. 2, p. 109-127, 2009.

GORDON, George G. The relationship of corporate culture to industry sector and corporate perfomance. In: R.H. Kilmann, M. J. Saxton, R, serpa and associate, gaining

control of the corporate culture. San Francisco: Jossey-Bass, 1985.

GRAVES, Samuel B.; WADDOCK, S. A. Institutional owners and corporate social performance. Academy of Management journal, v. 37, n. 4, p. 1034-1046, 1994.

GRIFFIN, Jennifer J; MAHON, John F. The corporate social performance and corporate financial performance debate twenty-five years of incomparable research. Business \& Society, v. 36, n. 1, p. 5-31, 1997.

GUPTA, Abhinav; BRISCOE, Forrest; HAMBRICK, Donald C. Red, blue, and purple firms: Organizational political ideology and corporate social responsibility. Strategic Management Journal, v. 38, n. 5, p. 1018-1040, 2017.

HAIR JR, Joseph F.; BABIN, Barry; MONEY, Arthur H.; SAMOUEL, Phillip. Fundamentos de métodos de pesquisa em administração. Porto Alegre: Bookman, 2005.
HALL, Richard H. Organizações

Estruturas e Processos. Rio de Janeiro: Prentice Hall do Brasil, 1984.

HARTNELL, Chad A; OU, Amy Y.; KINICKI, Angelo J.; CHOI, Dongwon; KARAM, Elizabeth P. A meta-analytic test of organizational culture's association with elements of an organization's system and its relative predictive validity on organizational outcomes. Journal of Applied Psychology, 2019.

HEJJAS, Kelsy; MILLER, Graham; SCARLES, Caroline. "It's like hating puppies!" Employee disengagement and corporate social responsibility. Journal of Business Ethics, p. 1-19, 2018.

HOFSTEDE, Geert; NEUIJEN, Bram; OHAYV, Denise D.; SANDERS, Geert. Measuring organizational cultures: A qualitative and quantitative study across twenty cases. Administrative science quarterly, p. 286-316, 1990.

HOFSTEDE, Geert. The business of international business is culture.

International business review, v. 3, n. 1, p. 1-14, 1994.

HOWARD, Larry W. Validating the competing values model as a representation of organizational cultures. The International Journal of Organizational Analysis, v. 6, n. 3, p. 231-250, 1998.

HUEMER, Lars. Corporate social responsibility and multinational corporation identity: Norwegian strategies in the Chilean aquaculture industry. Journal of Business Ethics, v. 91, n. 2, p. 265-277, 2010.

JAMALI, Dima; KARAM, Charlotte. Corporate social responsibility in developing countries as an emerging field of study. International Journal of 
Management Reviews, v. 20, n. 1, p. 3261, 2018.

KIMBERLY, John R.; QUINN, Robert E. New futures: the challenge of transition management. The management of transitions, New York: Dow Jones-Irwin, 1984.

KWAN, Paula; WALKER, Allan. Validating the competing values model as a representation of organizational culture through inter-institutional comparisons. Organizational Analysis, v. 12, n. 1, p. 21-37, 2004.

LEANDRO, Alexandra; REBELO, Teresa. A responsabilidade social das empresas: incursão ao conceito e suas relações com a cultura organizacional. Exedra: Revista Científica, n. 1, p. 11-40, 2011.

LENZIARDI, Raquel. A Gestão Sustentável de Pequenas Empresas Hoteleiras em Paraty (RJ): Percepções e Práticas. Gestão e Sociedade, v. 11, n. 28, p. 1558-1582, 2016.

LICHTENSTEIN, Donald R.; DRUMWRIGHT, Minette E.; BRAIG, Bridgette M. The effect of corporate social responsibility on customer donations to corporate-supported nonprofits. Journal of marketing, v. 68, n. 4, p. 16-32, 2004.

MALHOTRA, Naresh. K. Pesquisa de Marketing: uma orientação aplicada. Porto Alegre: Bookman, 2011.

MANNING, Louise. Corporate and consumer social responsibility in the food supply chain. British Food Journal, v. 115, n. 1, p. 9-29, 2013.

MAON, François; LINDGREEN, Adam; SWAEN, Valérie. Organizational stages and cultural phases: A critical review and a consolidative model of corporate social responsibility development. International
Journal of Management Reviews, v. 12, n. 1, p. 20-38, 2010.

MARGOLIS, Joshua D.; WALSH, Jamwa P. Misery loves companies: Rethinking social initiatives by business. Administrative science quarterly, v. 48, n. 2, p. 268-305, 2003.

MATTIOLI, José W.; CASTRO, Dagmar S. P.; CLARO, José A. C. S.; VIEIRA, Almir M.; SPERS, Valéria R. E. Corporate social responsibility and its role in the small business scenario. Nucleus (Ituverava), v. 12, p. 285-302, 2015

MCGUIRE, Jean B.; SUNDGREN, Alison; SCHNEEWEIS, Thomas. Corporate social responsibility and firm financial performance. Academy of management Journal, v. 31, n. 4, p. 854$872,1988$.

MCWILLIAMS, Abagail; SIEGEL, Donald S.; WRIGHT, Patrick M. Corporate social responsibility: Strategic implications. Journal of management studies, v. 43, n. 1, p. 1-18, 2006.

MIGUELES, Carmen P. O estudo da cultura organizacional: as dificuldades estão no objeto ou nas formas de defini-lo? Cadernos EBAPE. BR, v. 1, n. 2, p. 0116, 2003.

MITCHELL, Ronald K.; AGLE, Bradley R.; WOOD, Donna J. Toward a theory of stakeholder identification and salience: Defining the principle of who and what really counts. Academy of management review, v. 22, n. 4, p. 853-886, 1997.

PASRICHA, Palvi; SINGH, Bindu; VERMA, Pratibha. Ethical leadership, organic organizational cultures and corporate social responsibility: An empirical study in social enterprises. Journal of Business Ethics, v. 151, n. 4, p. 941-958, 2018. 
PETERS, Thomas J.; WATERMAN, Robert H. Jr. In search of execellence. New York: Harper \& Row, 1982.

RENWICK, Douglas WS; REDMAN, Tom; MAGUIRE, Stuart. Green human resource management: A review and research agenda. International Journal of Management Reviews, v. 15, n. 1, p. 114, 2013.

RISHI, Parul; MOGHE, Swati. Integrating corporate social responsibility and culture as a strategy for holistic corporate success in India. Journal of Corporate Citizenship, n. 51, p. 17-37, 2013.

RODRIGO, Pablo; ARENAS, Daniel. Do employees care about CSR programs? A typology of employees according to their attitudes. Journal of Business Ethics, v. 83, n. 2, p. 265-283, 2008.

ROUSSEAU, Denise M. Assessing organizational culture: The case for multiple methods. In B. Schneider (Org.), Organizational climate and culture, San Francisco: Jossey-Bass p.153- 192, 1990.

SANTOS, Neusa M. B. F. Cultura e desempenho organizacional: um estudo empírico em empresas brasileiras do setor têxtil. Revista de Administração

Contemporânea-RAC, v. 2, n. 1, p. 4766, jan./abr, 1998.

SCHEIN, Edgar H. Coming to a new awareness of organizational culture. Sloan management review, v. 25, n. 2, p. 3, 1984.

SCHEIN, Edgar H. Organizational Culture and Leadership. San Francisco: Jossey-Bass, 1985.

SCHEIN, Edgar H. What is culture. In P. J. Frost, L. F. Moore, M. R. Louis, C. C. Lundberg \& J. Martin (Orgs.), Reframing organizational culture. Newbury Park:

Sage, 1991.

SCHEIN, Edgar H. Three cultures of management: The key to organizational learning. MIT Sloan Management Review, v. 38, n. 1, p. 9, 1996.

SEN, Sankar. BHATTACHARYA, Chitra B. Does Doing Good Always Lead to Doing Better? Consumer Reactions to Corporate Social Responsibility. Journal of Marketing Research, v. 38, p. 225-243, 2001.

SIQUEIRA, Douglas M.; VIEIRA, Almir M. Valores organizacionais: percepção e legitimação. Revista Gestão \&

Tecnologia, v. 12, n. 2, p. 168-191, 2012.

SMIRCICH, Linda. Concepts of culture and organizational analysis.

Administrative science quarterly, p. 339358, 1983.

SONG, Whenhao; REN, Shengce; YU, Jun. Bridging the gap between corporate social responsibility and new green product success: The role of green organizational identity. Business Strategy and the Environment, v. 28, n. 1, p. 88-97, 2019.

STRAHILEVITZ, Michal; MYERS, John G. Donations to Charity as Purchase Incentives: How Well They Work May Depend on What You are Trying to Sell. Journal of Consumer Research, v. 24, March, p. 434-446, 1998.

STRAUTMANIS, Janis. Employees' values orientation in the context of corporate social responsibility. Baltic Journal of Management, v. 3, n. 3, p. 346-358, 2008.

SULKOWSKI, Adam J.; EDWARDS, Melissa; FREEMAN, R. Edward. Shake your stakeholder: Firms leading engagement to cocreate sustainable value. 
Organization \& Environment, v. 31, n. 3, p. 223-241, 2018.

TANTALO, Caterina; PRIEM, Richard L. Value creation through stakeholder synergy. Strategic Management Journal, v. 37, n. 2, p. 314-329, 2016.

TOMÉ, Alexandre S.; VIEIRA, Almir M. Cultura organizacional e formação identitária: um estudo com gerentes do setor bancário. Caderno de

Administração (UEM), v. 25, p. 44-57, 2017.

TURKER, Duygu. How corporate social responsibility influences organizational commitment. Journal of Business Ethics, v. 89, n. 2, p. 189-204, 2009.

WALDMAN, David; DE LUQUE, Mary S.; WASHBURN, Nathan; HOUSE, Robert J.; ADETOUN, Bolanle; BARRASA, Angel; DORFMAN, Peter et al. Cultural and leadership predictors of corporate social responsibility values of top management: A GLOBE study of 15 countries. Journal of International Business Studies, v. 37, n. 6, p. 823-837, 2006.

WANG, Lei; JUSLIN, Heikki. The impact of Chinese culture on corporate social responsibility: The harmony approach.

Journal of Business Ethics, v. 88, n. 3, p. 433-451, 2009.

WOOD, Donna J. Corporate Social Performance Revisited. Academy of Management Review, v. 16, n. 4 p. 691718, 1991.

YEUNG, Arthur; BROCKBANK, Joseph W.; ULRICH, David. Organizational culture and human resource practices: An empirical assessment. Research in Organizational Change and Development, v. 5, n. 59-81, 1991.

\footnotetext{
i Doutora em Administração pela UNISINOS, área de concentração: Organizações e Competitividade, Mestre em Administração pela Faculdade Meridional - IMED (2017), especialista em Gestão Empresarial pela Faculdade Meridional - IMED (2014) e bacharel em Administração pela Universidade de Passo Fundo (2012).

ii Pós-doutorado em Sociologia Econômica pela Université Paris IV - Sorbonne, Doutorado em Sociologia pela UFRGS com estágio doutoral na Université Paris IV - Sorbonne, Mestrado em Sociologia pela UFRGS, Licenciado em Filosofia pela UPF e Bacharel em Filosofia pelo IFIBE.

iii Doutoranda em Administração / Organizações e Competitividade (início em 2018) e mestra em Design Estratégico pela Universidade do Vale do Rio dos Sinos (2017). Graduada em Comunicação Social / Relações Públicas pela Pontifícia Universidade Católica do Rio Grande do Sul (1987), cursou MBA em Marketing Estratégico pela FGVRS (2004) e Gerenciamento de Projetos.
} 